STUDIA ROSSICA POSNANIENSIA, vol. XXXIX: 2014, pp. 253-262. ISBN 978-83-232-2747-2. ISSN 0081-6884. Adam Mickiewicz University Press, Poznań

\title{
СЕМАНТИЧЕСКАЯ ДЕРИВАЦИЯ В ИСТОРИИ РУССКОГО ЯЗЫКА
}

\author{
SEMANTIC WORD FORMATION \\ IN THE HISTORY OF THE RUSSIAN LANGUAGE
}

\author{
ГЕННАДИЙ НИКОЛАЕВ
}

\begin{abstract}
The article is devoted to the problem of semantic word-formation in the history of the Russian language. Considering the way in which secondary language signs are formed, it is possible to speak about the semantic derivation with reference to the final period of semantic syncretism in the history of Russian (end of the $14^{\text {th }}$ century).

Геннадий Николаев, Казанский университет, Казань - Россия.
\end{abstract}

Семантическая деривация - это, как известно, образование новых вторичных номинативных единиц путем изменения семантики базовой первичной единицы без изменения ее формальной (прежде всего морфемной) стороны. Установлено, что семантическая деривация свойственна как для лексики, так и для морфологии, являясь одним из свидетельств взаимосвязи и взаимодействия слово- и формообразования. Например: голова (часть тела) и голова (староста украинской или южнорусской деревни), успевать (к сроку) и успевать (в школе) и др. - семантическая деривация в лексике; „Завтра я иду в mеатр” или „Отнимите у меня перо - и я помер" (Чехов) - семантическая деривация в морфологии. Казанские историки языка, вслед за В.М. Марковым, опираясь на идеи А.А. Потебни ${ }^{1}$ и Л.В. Щербы ${ }^{2}$, квалифицируют семантическую

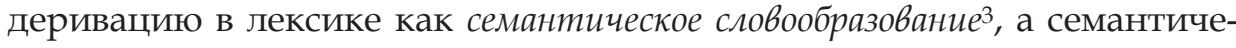
скую деривацию в морфологии как семантическое формообразование 4 .

1 А.А. П о т е б н я, Из записок по русской грамматике, т. 1-2, Москва 1958, с. 15-16.

2 Л.В. Щ е р б а, Языковая система и речевая деятельность, Ленинград 1974, c. $290-291$.

${ }^{3}$ В.М. М а р к о в, О семантическом способе словообразования в русском языке, Ижевск 1981. См. также: Н.М. Ш а н с к и й, Лексическая деривация в русском языке, „Русский язык в школе” 1977, № 3, с. 9-16.

4 Г.А. Н и к о л а е в, Семантическое формообразование в русском языке, [в:] Семантическая деривация и ее взаимодействие с морфемной, Омск 2003, с. 88-97. 
Вопрос этот дискуссионный. Большинство лингвистов считает, что результатом семантической деривации в лексике является не новое слово, а новое значение базового слова, его лексико-семантический вариант. Что касается семантической деривации в морфологии, то ее относят к контекстуальному употреблению соответствующей формы слова. Не вдаваясь в дискуссию по этой проблеме (ее до сих пор не получилось из-за позиции сторонников полисемии, которые отрицают мнение оппонентов, требуют от них солидных аргументов, не приводя в защиту полисемии ни одного своего, так как считают ее само собой разумеющейся истиной), а опираясь на те аргументы, которые существуют в упомянутой выше литературе, приведу здесь одно мнение А.А. Потебни относительно контекстных употреблений слов и форм слова:

Значение слова возможно только в речи. Вырванное из связи, слово мертво, не функционирует, не обнаруживает ни своих лексических, ни тем более формальных свойств, потому что их не имеет 5 .

Особенно это касается грамматической формы слова, так как „нет формы, присутствие и функция коей узнавалась бы иначе, как по смыслу, т.е. в связи с другими словами и формами в речи и языке"б.

Термин „семантическая деривация” связывают с именем Д.Н. Шмелева. Однако суть этого явления рассмотрена еще в XIX веке А.А. Потебней и М.М. Покровским. Собственно говоря, именно эти двое ученых и являются основателями раздела исторической семасиологии русского языка (и других языков индоевропейского типа). При этом, если Д.Н. Шмелев видит результатом семантической деривации лексико-семантический вариант слова (лсв), то А.А. Потебня, не применяя термина семантическая деривация, относит результаты соответствующих семантических процессов к новым словам (омонимам).

Современные сторонники полисемии окончательно запутали вопрос о единстве и тождестве слова. Так, оказывается, что слово глубокий имеет разные значения, позволяющие выступать ему в сочетаниях глубокая река, глубокая страсть, глубокая мысль и др. Слово голова у составителей современных словарей имеет двойную родовую характеристику: женского рода - в значении 'часть тела' и мужского рода - в значении 'староста деревни'. А категория одушевленности-неодушевленности вообще не учитывается. Признавая единство лексического и грамматического в слове, они не следуют этому положению в исследовательской практике. Показательно, что к омонимам они относят только такие

5 А.А. П о т е б н я, Из записок по русской грамматике..., указ. соч., т. 1-2, с. 42.

6 Там же, с. 45. 
хрестоматийные случаи, как ключ и коса. Д.Н. Шмелев, в отличие от своих единомышленников, признает право на существование и другой точки зрения на явление полисемии, хотя и не разделяет ее, и старается обосновать свои взгляды ${ }^{7}$. Но убедительных аргументов Д.Н. Шмелев и другие сторонники полисемии пока не нашли.

B.M. Марков считает, что основанием выделения нового слова при семантическом словообразовании является постановка слова в иной лексический ряд (т.е. смена денотата). Например, с одной стороны, - нос, рот, уши, юоб, губы и т.д.; с другой, - нос, корма, ют, бак, палуба, камбуз и т.п. С.П. Лопушанская, принимая эту точку зрения, но учитывая разные стадии развития семантики слова, выделяет семантическую деривацию (при смене денотата) и семантическую модуляцию (при сохранении денотата) 8 . Примером семантической модуляции может служить приведенное Д.Н. Шмелевым в упомянутой работе прилагательное новый

И тем не менее в этих вопросах еще очень много неясного. Чтобы проиллюстрировать эту свою мысль, я хочу привести здесь анекдот А.П. Чехова, который использует и В.М. Марков в своей брошюре О семантическом способе словообразования в русском языке. Это короткий анекдот Когда козел бывает свинъей? из подборки Майонез:

Повадился к нашим козам чей-то козел ходить, - рассказывал один помещик. - Мы взяли и побили его. Он продолжал все-таки ходить. Мы его выпороли и к хвосту его палку привязали. Но и это не помогло. Подлец все еще продолжал лазить к нашим козам. Хорошо же! Мы его поймали, насыпали ему в нос табаку и вымазали скипидаром. После этой экзекуции он не ходил три дня, а потом опять начал ходить. Ну не свинья ли он после этого?

В.М. Марков однозначно считает, что здесь мы имеем дело с омонимией. Ученый пишет:

Использование семантических вариаций одного и того же слова, конечно, не вызвало бы того комического эффекта, который достигается неожиданным столкновением именно омонимов, самая разность которых в данном случае функционально важна ${ }^{10}$.

Здесь мы имеем дело с шуточной „игрой слов”, „которая весьма определенно указывает на наличие двух самостоятельных лексем" [там же]. Действительно, каламбуры строятся обычно на омонимии. Ср., напри-

7 Д.Н. Ш м е л е в, Современный русский язык. Лексика, Москва 1977, с. 81-86.

8 С.П. Л о п у ш а н с к а я, Семантическая модуляиия как речемыслительный процесс, „Вестник ВолГУ. Сер. 2: Филология” 1996, вып. 1, с. 6-13.

9 Д.Н. Ш м е л е в, указ. соч., с. 86.

${ }_{10}$ В.М. М а р к о в, указ. соч., с. 17. 
мер, каламбурные анекдоты из „Письмовника” Н. Курганова, обыгрывающие омонимию трогать (касаться и волновать) и прозябать (прорастать и замерзать). Или каламбур Н.В. Гоголя: „Тут голова поднял палец вверх и голову привел в такое положение, как будто бы она прислушивалась к чему-нибудь" (Майская ночъ).

Сторонники семантического словообразования считают, что семантическая деривация может сопровождаться фонетическими и грамматическими изменениями, вплоть до смены части речи при субстантивации, адвербиализации и адъективации. Так, смена ударения при семантической деривации в случае острота́ > остро́та способствовала отнесению семантического производного в другой словообразовательный тип. Если слово острота́, как и другие имена на -ота́ с ударением на окончании (ср.: краснота́, быстрота́ и т.п.), мотивируется прилагательным, то слово остро́та, как имена этого типа с безударным окончанием (ср.: дремо́ma, забо́та, зебóma и т.п.), мотивируется глаголом, в данном случае - острить. Смена ударения повлекла за собой и смену словообразовательной мотивированности, подтверждая, что в данном случае мы имеем дело с омонимией. Добавим также то, что слово остро́та имеет полную числовую парадигму форм, в то время как слово острота́, как образование с отвлеченным значением, относится к singularia tantum.

Здесь мы выходим на проблему взаимодействия семантической деривации и морфемного словообразования и формирования на этой основе словообразовательной омонимии. Мы не будем затрагивать этих вопросов, так как они достаточно исследованы в работах казанских ученых ${ }^{11}$.

Когда речь заходит об истории языка, то обычно имеются в виду ее ранние периоды. Как же обстоит дело с семантической деривацией в древнерусскую эпоху? В.В. Колесов считает, что многозначности в этот период не было, поскольку древнее слово синкретично.

В самом деле, - пишет он, - древнейшее „значение” предстает как синкретическое представление о денотате, которое в процессе коммуникации как бы заменяет предмет во всей совокупности его признаков, в т.ч. и случайных, внешних, всегда конкретных, легко узнаваемых [...]. Подобные слова-синкреты не имели многозначности (как можно было бы воспринимать подобный синкретизм значения с позиций современного взгляда на значение слова), поскольку многозначность противопоставлена синкретизму исходного значения, как противопоставлено само отношение к денотату: он воспринимается целиком, а не по сумме своих признаков ${ }^{12}$.

11 Г.А. Н и к о л а е в, Лекциии по русскому словообразованию, Казань 2009, с. 108-112.

12 В.В. К о л е с о в, Исторические основания многозначности и лингвистические средства ее устранения, [в:] Русское семантическое словообразование, Ижевск 1984, с. 18. 
Семантический синкретизм древнего слова доказан в ряде исследований, начиная с работ А.А. Потебни. Он был свойствен всем типам языковых значений: категориальным (недифференцированность субстантива и адъектива), грамматическим (настоящее - будущее время, актив - пассив и др.), словообразовательным (действие и его обстоятельства - результат, орудие, объект, субъект и т.Д.), наконец, лексическим.

Суть синкретизма заключалась в диффузности (недифференцированности) значения слова, невозможности контекстного расчленения значений. Наиболее ярко он представлен в случае, приводимом А.А. Потебней: „Бог спас наш”. Это может значить и „бог спаситель” и „бог спасение наше” 13 . Говорить о полисемии здесь действительно не приходится.

Трудно сказать, применим ли к слову с синкретичной семантикой компонентный анализ. Но учитывая то, что и компонентный анализ тоже имеет свое начало и развитие, можно представить семантическую структуру древнего слова в виде набора сем, среди которых в том или ином употреблении выделяется семная доминанта, а остальные семы тоже присутствуют в каждом словоупотреблении. В результате мы и имеем диффузность значений слова.

Считается, что синкретизм разрушился к XIV веку. Но он сохранился в целом ряде случаев. Так, мы до сих пор не можем представить значение глагола в виде чистого действия, а всегда мыслим его в связи с субъектом. Например, глагол лететъ. Мы не можем отделить при помощи контекстов значение действия и его результата в существительных, обозначающих звук (крик, смех, писк и т.п.). Наконец, синкретична семантика поэтического слова. Например, лермонтовский парус.

Хороший материал по лексическому синкретизму дает Слово о полку Игореве. Синкретично уже слово плькъ в заглавии поэмы. Поэт и исследователь Андрей Чернов, отмечая, что это слово могло обозначать в древнерусском языке полк, поход и битву, справедливо считает, что в заглавии оно одновременно обозначает все эти три реалии. Это и есть синкретизм. А. Чернов называет его „поэтической полисемией" 14 .

В дискуссии о подлинности этого восточнославянского шедевра, которая ведется с перерывами чуть ли не со времени находки поэмы, как раз и не учитывается этот момент. Слово о полку Игореве написано в эпоху языкового синкретизма (конец XII века). И это должно проявиться, в частности, при сравнении его с Задонщиной, которую скепти-

13 А.А. П о т е б н я, Из записок по русской грамматике, т. 3, Москва 1986, с. 93.

14 А. Ч е р н о в, Поэтическая полисемия и сфррагида автора $b$ "Cлове о полку Игореве", [в:] Исследования "Слова о полку Игореве”, Ленинград 1986, с. 271. 
ки считают тем произведением, с которого будто бы было списано Cлово о полку Игореве. Задонщина, созданная в конце XIV - начале XV вв., уже не отражает синкретизма языковых явлений.

Показательно в этом отношении известное место из Слова: иръныя тучя съ моря идутъ, хотятъ прикрытии 4 солнца ${ }^{15}$, а въ нихъ трепешуть синіи мльніи. Исследователей, естественно, привлекает необычное сочетание синіи мльніи. Большинство переводов Слова на современный язык сохраняют его (переводы В.А. Жуковского, А.Н. Майкова, Н. Заболоцкого, В.И. Стеллецкого, Л.И. Тимофеева, Д.С. Лихачева и др.). Исключение составляет первое печатное издание памятника: сверкаетъ въ нихъ молнїя. Издатели опускают высоко поэтическое слово трепещуть и синіи, как бы объединяя их значения в слове сверкаетъ - 'ярко, ослепительно вспыхивает' (СРЯ XI-XVII).

Однако исследователи (особенно лексикографы) дают этому месту свои интерпретации. И.И. Срезневский определяет семантику слова синий в этом фрагменте как „синеватый, отливающий голубым цветом (как эпитет молнии)”'16; В.Л. Виноградова: „Имеющий оттенок темно-синего цвета"17; „Постоянный эпитет для обозначения цвета молнии"18. Как видим, разные лексикографы вкладывают разное цветовое содержание в слово синий: от светлого до темного.

М.Ф. Мурьянов посвятил специальную статью синим молниям в Слове о полку Игореве. Он считает, что выражение синие молнии „следует понимать как молнии ослепительные, от которых темнеет в глазах"19. Автор находит соответствия этому выражению в других индоевропейских языках (в частности в немецком - blitzblau или Blaufeuer). Но, главное, он принимает верное направление исследования - подкрепить это словесное выражение зримым физическим фактом, т.е. изображением молнии в средневековой живописи. В 1984 году я с группой студентов был в диалектологической экспедиции в Псковской области. При посещении Спасо-Преображенского собора Мирожского монастыря XII века в Пскове мы увидели, что на фреске, изображающей

15 В первом печатном издании поэмы, по которому цитируется фрагмент, использована буквенная цифра (Ирочческая $n$ вснь о поход в на половиовъ уд ъльнаго князя Новагорода-Свверскаго Игоря Святославича..., Москва 1800, с. 12).

16 И.И. С р е з н е в с к и й, Материалы для „Словаря древнерусского языка”, т. 3, Москва 1958 (переиздание), с. 356.

17 В.Л. В и н о г р а д о в а, Словарь-справочник „Слова о полку Игореве”, вып. 5, Ленинград 1978, с. 145.

18 Словарь русского языка XI-XVII въ., вып. 24, Москва 1999, с. 150. Сокращения названий памятников даны по этому словарю.

${ }^{19}$ М.Ф. М у р ь я н о в, „Синие молнии”, [в:] Поэтика и стилистика русской литературы, Ленинград 1971, с. 28. 
„Всемирный потоп”, сверкающие молнии переданы синим цветом. Этот факт говорит о многом, но прежде всего о том, что эти фрески и Слово о полку Игореве современники.

Чем же объяснить этот феномен „синих молний”? Наверное, следует согласиться с комментарием В.И. Стеллецкого к изданию Слова о полку Игореве: „Слово синий в древнерусском языке могло употребляться в значении «сияющий», «яркий»" 20. Ср. замечание В.В. Колесова: „синим иногда называли все сияющее темным блеском” 21. Этимологи подтверждают, что слово синии восходит к тому же корню, что и глагол сиять, и первоначально имело значение „сияющий, блестящий”22. Таким образом, слово синий представляло собой синкрету, совмещающую цветовое значение со значением „яркий".

Как синкрета это слово выступало в сочетании „синие молнии”, которое зафиксировано в Слове о полку Игореве и раннем Кирилло-Белозерском списке Задонщины. В ее поздних списках это сочетание превращается в сильные молнии, поскольку переписчику был уже не ясен смысл синкретичного древнего слова синий. Это лишний раз подчеркивает, что текст Слова о полку Игореве более древний, чем текст Задонщины.

Слово синий в значении, близком к тому, с которым оно выступает в сочетании синие молнии, отмечено в следующем контексте: „Явися яко пламень н бкий синь" (Ж. Пр. Уст., 146). Интересная связь обнаруживается между древнерусскими контекстами и поэтическими образами раннего М. Горького: „Синим пламенем пылают стаи туч над бездной моря. Море ловит стрелы молний и в своей пучине гасит" (Песня о Буревестнике).

Синкретичен в Слове о полку Игореве и союз коли в известном „золотом слове Святослава, со слезами смешанном": „ККоли соколъ въ мытехъ бываетъ, высоко птиць възбиваетъ, не дасть гнезда своего в обиду". B.M. Марков доказал, что союз здесь имеет не временное значение (как его обычно переводят) и не условное, а уступительное, с временным (а возможно, и условным) оттенком („даже если когда сокол линяет") 23.

Формирование семантической деривации в русском языке, безусловно, могло проходить только после разрушения семантического синкретизма, т.е. начиная с конща XIV века. Выделяющиеся при распа-

20 В.И. С т е л л е ц к и й, Комментарий, [в:] „Слово о полку Игореве”. Древнерусский текст и переводы, Москва 1981, с. 248.

21 В.В. К о л е с о в, Свет и ияет 8 „Слове о полку Игореве”, [в:] „Слово о полку Игореве": 800 лет, Москва 1986, с. 220.

22 П.Я. Ч е р н ы х, Очерк русской исторической лексикологии. Древнерусский период, Москва 1956, с. 90; Н.М. Ш а н с к и й и др., Краткий этимологический словарь русского языка, Москва 1961, с. 302.

23 Г.А. Н и к о л а е в, Виталий Михайлович Марков. 1927-2010, Казань 2011, с. 19. 
де синкреты значения оформлялись в самостоятельные слова чаще путем морфологического словопроизводства, что отразилось на росте продуктивности словообразовательных типов и моделей. Поскольку разрушение синкретизма проходило не одномоментно, а постепенно, прояснение семантики слов при помощи морфемного их осложнения фиксируется на протяжении всего древнерусского периода.

А.А. Потебня, углубленно изучавший процессы устранения „двусмысленности имени" (т.е. разграничения субстантива и адъектива), считал, что эту функцию выполняли, в частности, суффиксы -* и -*ik- (русские -ьць и -икъ). Классическими являются слова ученого: „Побуждением к присоединению к такому существительному молодъ суффикса -ьць могло быть именно желание отделить его от прилагательного молодъ и таким образом обособить категорию прилагательного" 24 .

Словообразовательные средства использовались и для разграничения значения действия и лица. Так, слова типа ловъ, бой, совмещавшие в своей синкретичной семантике эти значения (ср.: уловъ, но зъъроловъ, розбой, но звъробой и т.п.), проясняли свою семантику путем присоединения того же суффикса -ъцъ ( юовъ - ловьцьь, бой - боецьь и т.п.).

Однако не все выделяющиеся семантические единицы получали морфологическое оформление. Так, например, большую группу имен составили существительные адъективного (местоименного) склонения типа тысячьский, челобитная, подушьное и т.п. В связи с укреплением адъектива в системе языка они в процессе развития субстантивно-адъективных отношений попали в зависимость от прилагательных. В настоящее время они рассматриваются как семантические дериваты отадъективного типа и получили название субстантиваты.

К этим случаям нельзя применить понятия полисемия, так как они находятся в системе разных частей речи. Правда, как мы отмечали, для сторонников многозначности это, к сожалению, не является препятствием. Однако мы ориентируемся на иные принципы.

В большинстве случаев происходит выделение семантических единиц в ходе распада синкретизма в пределах одного слова и одной части речи. Возникающая в этом случае „полисемия" представляла промежуточное явление в семантической истории слова.

Освобождающиеся значения не могли сразу быть восприняты как новые самостоятельные языковые единицы. Они организуются в семантическую парадигму слова, в которой каждое из значений определяется отношением его к другому значению на основании, с одной стороны, чисто языковых факторов (соотношение отвлеченного и конкретного, собирательного и единичного

${ }^{24}$ А.А. П о т е б н я, Из записок по русской грамматике..., указ. соч., т. 3, с. 48. 
и т.Д.), с другой стороны, экстралингвистических факторов соотнесенности между собой обозначаемых реалий 25 .

При этом между отдельными значениями возникают отношения первичности-вторичности, или деривационные отношения. Формируются семантические модели на основании обобщения сходных отношений в типе слов. Эти модели намечаются еще в эпоху синкретизма. Они укрепятся в дальнейшем и станут моделями семантической деривации.

Рассматривая семантические процессы в истории русского языка, мы должны учитывать еще одну особенность, характерную для языковой древности: „вторичный характер отвлеченности в истории развития человеческой мысли и языка" 26 . Первичная конкретность языковой семантики сочеталась с ее синкретичностью. А.А. Потебня считал, что „первоначальная конкретность имени" (в частности действия) была необособленна от других его обстоятельств (в частности, результата, места и т.д. $)^{27}$. Это имело значение для развертывания семантических процессов в языке. Поэтому мы должны признать, что отвлеченные значения в слове искони являлись результатом семантического развития древнего слова, результатом семантической деривации, как бы мы сказали применительно к более позднему периоду истории языка.

Изменения произошли в связи с развитием глагольно-именных словообразовательных отношений, в ходе которого имена действия в качестве активной производящей базы получили инфинитивные основы. Значение действия становится в этих именах доминантным, а конкретные значения (результата, места, орудия действия и др.) осмысляются как вторичные, семантически производные. Продуктивной становится модель 'отвлеченное $\rightarrow$ конкретное'. Однако древняя модель 'конкретное $\rightarrow$ отвлеченное', хотя и теряет активность, но до сих пор проявляет себя в языке. Например, в случаях типа чай в значении “чаепитие' („пригласить на чай”), снег в значении 'снегопад' и т.п.

Случаи „прямой” и „обратной” семантической деривации отмечаются и в соотношении значений единичности и собирательности. В истории русского языка зафиксированы модели 'единичное $\rightarrow$ собирательное' (типа „Лист сухой валится” - А. Фет) и 'собирательное $\rightarrow$ единичное' (прислуга - орудийная и в доме; моя родня и он мне родня).

${ }^{25}$ Г.А. Н и к о л а е в, Историческая семасиология русского языка и связанные с ней проблемы, [в:] Русский язык и современность. Проблемы и перспективы разбития русистики, Москва 1991, с. 209.

${ }^{26}$ Н.П. Р о м а н о в а, Вопросы словообразования в научном наследии А.А. Потебни, [в:] Наукова спадщина О.О. Потебні і сучасна філологія, Київ 1985, с. 139.

27 А.А. П о т е б н я, Из записок по русской грамматике..., указ. соч., т. 3, с. 23. 
Классическим примером конкретизации собирательных имен являются слова женщина и мужиина 28.

Единичность в русском языке чаще оформлялась при помощи суффиксов -ин, -ина. Например: мордва - мордвин, скот - скотина, где производящее выступает в собирательном значении, а производное - в значении единичности. Однако во второй паре слов морфологическое словообразование было осложнено семантической деривацией. В результате слово скот может называть единичное животное (хотя и редко), а скотина (часто) имеет собирательное значение. Ср.: „Скажите, пожалуйста, отчего это вашу тяжелую тележку четыре быка тащат шутя, а мою пустую шесть скотов едва подвигают" (Лермонтов, Бэла); „Корову свою не продам никому. Такая скотина нужна самому!” (Михалков, Чудак).

Сформировавшаяся в русском языке семантическая деривация является объективным феноменом. Все ученые сходятся в ее признании. Разногласия начинаются тогда, когда дело касается результатов семантической деривации: одни квалифицируют их как лексико-семантические варианты слова, другие - как самостоятельные слова-омонимы. Мы придерживаемся второй точки зрения.

28 В.В. В и н о г р а д о в, Избранные труды. Исследования по русской грамматике, Москва 1975 , с. $186-187$. 